\title{
THE APPLICATION OF MODIFIED NORMALIZED DIFFERENCE WATER INDEX BY LEAF AREA INDEX IN THE RETRIEVAL OF REGIONAL DROUGHT MONITORING
}

\author{
Hong-wei Zhanga, , ${ }^{\mathrm{a} *}$, Huai-liang Chen ${ }^{\mathrm{a}, \mathrm{b}}$ \\ ${ }^{a}$ CMA • Henan Key Laboratory of Agro-meteorological Safeguard and Applied Technique, Zhengzhou 450003, China. \\ -xxqxjzhw1966@163.com \\ bHenan Meteorological Administration, Zhengzhou 450003, China. -h.chen@vip.163.com
}

Commission AGRI-3

KEY WORDS: Vegetation Coverage, Relative Leaf Area Index (RLAI), Normalized Difference Water Index (NDWI), Retrieval

\begin{abstract}
:
The vegetation coverage is one of the important factors that restrict the accuracy of remote sensing retrieval of soil moisture. In order to effectively improve the accuracy of the remote sensing retrieval of soil moisture and to reduce the impact of vegetation coverage variation on the retrieval accuracy, the Leaf Area Index (LAI) is introduced to the Normalized Difference Water Index (NDWI) to greatly improve the accuracy of the soil moisture retrieval. In its application on the regional drought monitoring, the paper uses the relative LAI from two places which locate in the north and south of Henan Province respectively (Xin Xiang and Zhu Ma Dian) as indicators. It uses the days after turned-green stage to conduct difference value correction on the Relative Leaf Area Index (RLAL) of the entire province, so as to acquire the distribution of RLAI of the province's wheat producing area. After this, the local remote sensing NDWI will be Modified $(M N D W I=N D W I \times R L A I) \quad$ to acquire the soil moisture distribution status of the entire province's wheat producing area. The result shows that, the Modified Normalized Difference Water Index of LAI which based on the days after turned-green stage can improve the real time retrieval accuracy of soil moisture under different vegetation coverage.
\end{abstract}

\section{INTRODUCTION}

Drought is caused by long-term lack of soil water content which would affect agriculture, ecology and socio-economy; it is particularly harmful to food production. Therefore, scientific research institutes have studied for years on droughts which affects food production and devoted a great deal of manpower and material resources on drought monitoring, forecasting, early warning and assessment; the government departments have also attached great importance to the relevant decision.

The studies show that the Normalized Difference Vegetation Index (NDVI) is widely accepted because it is easy to observe and use among other remote sensing retrieval indexes of soil moisture based on the reflectance spectrum. Meanwhile, NDVI can reflect the variation condition of soil moisture at a certain depth via the spectrum data variation of the vegetation index. Therefore, many NDVI-based soil moisture retrieval indexes are derived from it. Since these indexes can reflect soil moisture variation via vegetation moisture spectrum variation, it has theoretical and realistic significance to the development and variation of droughts.

The previous research results have shown that NDVI is both conservative and saturated, it cannot reflect the variation status of soil moisture in real time without any delay ( $\mathrm{Di}, \mathrm{L}$., et al., 1994; Kogan, F.N., et al., 1990; Liu, W., et al., 1991). With the increase of coverage, the saturation of the normalized difference vegetation index (NDVI) increases accordingly,

Author: Huai-liang Chen (1967- ), male, from Huixian, Henan, China. His research interests are remote sensing and applied meteorology.Email:h.chen@vip.163.com

* Corresponding author: Hong-Wei Zhang (1966-), male, from Wenxian, Henan, China, whose research interests are remote sensing and applied meteorology. Email:xxqxjzhw1966@163.com 
which effect on soil moisture retrieval is also increasing (Peters, A.J., et al., 2002; Unganai, F.N., et al., 1998; Yang, L., et al., 1998).

Based on the known knowledge of NDVI, Wang Lei and other researchers acquired the negative exponential relationship equation between NDVI and MDPI by comparing their sample data, which can be used to calculate the MPDI domain value of 3 kinds of vegetation coverage conditions, namely, dense vegetation, moderate vegetation, sparse vegetation and bare ground, thereby improving the soil moisture retrieval accuracy (Wang Lei, et al., 2006). Liu Wei and other researchers has combined the polar metric decomposition techniques and scattering model of vegetation coverage area methods to estimate the soil moisture variation under the high vegetation coverage surface(Liu Wei, 2005). Cheng Yu and other researchers acquired new parameters by introducing the normalized difference vegetation index to correct the thermal inertia, which verified that the corrected parameter is significantly associated with soil moisture content under different vegetation coverage (Cheng Yu, et al., 2006). Zhou Peng and other researchers adopted the "water-cloud model", removing the vegetation influence from the back scattering radar data and establish the relation between the back scattering soil coefficient and the soil moisture content. When conducting surface soil moisture retrieval of cotton, corn and other crops producing areas on the semi-arid and semi-drought area, removing the vegetation influence under the moderate vegetation can achieve a good result (ZHOU Peng, et al., 2010).

In the study of spectral response of the moisture variation, it is found out that short wave is more sensitive to moisture than other spectrum; therefore, the short infrared wave can be used for soil moisture retrieval. Meanwhile, the study shows that the vegetation coverage has much impact on the short infrared wave reflective frequencies (Nemani, R., et al., 1993; Ceccato P, et al., 2002; Du Xiao, et al., 2004). Based on the nearinfrared and short-infrared moisture spectrum variation, Gao and other researchers constructed the normalized difference moisture index (NDWI) in real-time retrieval of soil moisture, which has high retrieval accuracy (Bo-CaiGao, et al., 1996). The study shows that the normalized difference moisture index (NDWI) is also under the influence of vegetation coverage
Therefore, it is necessary to investigate the impact of vegetation index in NDWI retrieval of soil moisture. Besides, currently there are not many studies on this aspect, especially studies on the impact of vegetation coverage on retrieval accuracy in terms of regional soil moisture retrieval. This paper uses the variation features of leaf area index from two monitoring points of winter wheat in Henan province during its turned-green to mature periods and obtains the leaf area distribution of the main production areas of winter wheat in Henan province by interpolation method. Finally, it acquires the modified water index of leaf area index (MNDWI) by using the remote sensing spectral data to correct the normalized difference moisture index (NDWI), which will hopefully increase the retrieval accuracy of soil moisture.

\section{RESEARCH AREA AND RESEARCH DATA}

This paper selects the main growing areas of winter wheat $\&$ summer maize in Henan province as study areas, including 76 counties (cities) in 11 cities. Henan Province is located in the mid-east China, down in the middle and lower reaches of the Yellow River, spanned from $31^{\circ} 23^{\prime} \sim 36^{\circ} 22^{\prime}$ N, $110^{\circ} 21^{\prime}$ $\sim 116^{\circ} 39^{\prime} \mathrm{E}$. It is situated in the warm temperate and northern subtropical region with mild climate and clear transitivity. Its main cultivation methods are wheat-maize rotation.

The average annual precipitation in Henan Province over years is decreasing from above $1000 \mathrm{~mm}$ in the rainy area in the South of Henan to $500 \sim 600 \mathrm{~mm}$ in the semi-arid area in the northwest, showing an uneven temporal and spatial distribution of rainfall. The precipitation in wet years is 2.5 to 3.5 times to that in the dry year.

The soil moisture data used in this paper collected from soil moisture data monitored by the automatic soil moisture station when the winter wheat had turned green with high coverage, growing fast and sound from 2012 to 2013. The study has adopted the average soil moisture value of soil depth of 0 to $30 \mathrm{~cm}$.

The remote sensing data uses the 2012-2013 MODIS spectroscopic data collected by the satellite station of the Meteorological Sciences Institute of Henan Province and the data format is LD3. 


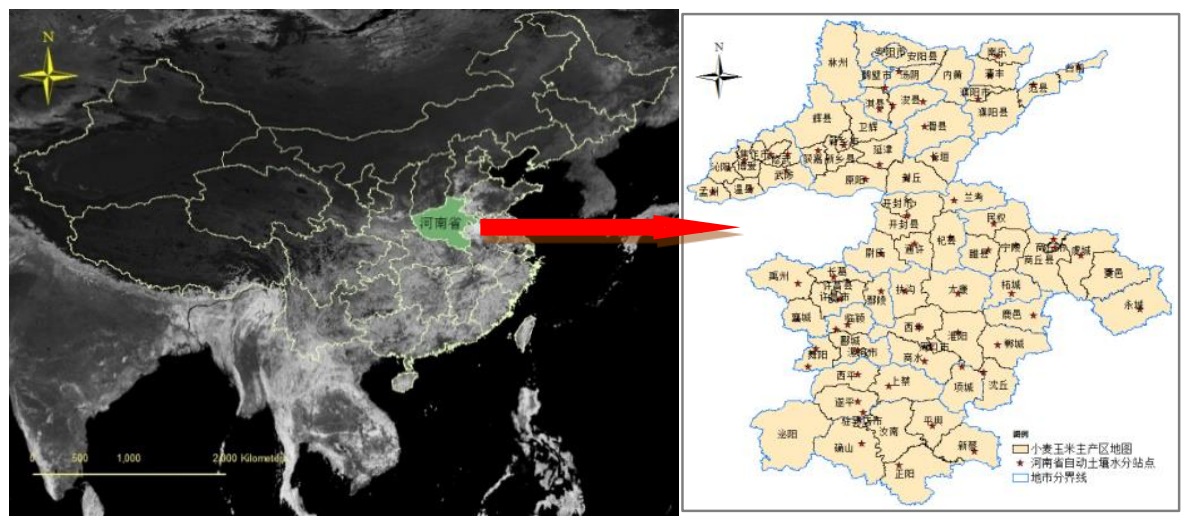

Fig.1 The Sketch Map of Soil Moisture Auto-monitoring Sites Distribution

\section{RESEARCH METHOD}

\subsection{Normalized Moisture Difference Index (NDWI)}

The Normalized Difference Vegetation Moisture Index is promoted by Gao in 1996(Bo-CaiGao, et al., 1996), It takes the near-infrared RNIR as reference wave band, using the shortinfrared wave band RSWIR for the retrieval of water content information. The relevant studies show that the normalized difference water index (NDWI) can more effectively reflect the water content variation than the normalized difference vegetation index (NDVI)(Ceccato P, 2002), Formula is as follows:

$$
N D W I=\frac{R_{N I R}-R_{S W I R}}{R_{N I R}+R_{S W I R}}
$$

In this formula, RNIR is the reflectance spectrum value of the ground target in the near-infrared band $(780-890 \mathrm{~nm}$, corresponding to the second band of MODIS), Rswir is the reflectance spectrum value of the ground target in the shorter infrared (1580-1750nm, corresponding to the seventh band of MODIS).

3.2 The Normalized Leaf Area Index (The Relative Leaf Area Index RLAI)

In the study, in order to reduce the impact of different factors on winter wheat, the leaf area index (LAI) of the winter wheat has been normalized (Relative Leaf Area Index RLAI) which can be expressed as:

$$
R L A I_{i}=\frac{L A I_{i}}{L A I_{M A X}}
$$

In the formula, $\mathrm{RLAI}_{\mathrm{i}}$ (Relative Leaf Area Index) is the normalized leaf area index (also called Relative Leaf Area Index) and $i$ stands for the number of times that the leaf area index has been observed; LAI MAX stands for the maximum leaf area index.

\subsection{The Construction of Modified Normalized Moisture} Difference Index (MNDWI)

After the modified with the relative leaf area index (RLAI), the normalized difference moisture index (NDWI) is represented as:

$$
M N D W I=\frac{R_{N I R}-R_{S W I R}}{R_{N I R}+R_{S W I R}} \times R L A I_{\mathrm{i}}
$$

The meaning of the related parameters is the same as (1), (2)

3.4 Determination the RLAI criteria in the South and North

\subsubsection{The Calculation and Analysis of Xin Xiang RLAI}

To calculate the average number of the leaf area indexes from the past two years based on the leaf area data collected by Xin Xiang Monitoring Station from 2012-2013, it uses formula (2) to calculating RLAI and analyzing them, the results are as follow:

Table 1 The Relative Leaf Area Index (RLAI) in 2012-2013a

\begin{tabular}{cccccccccc}
\hline Time & M*/Feb. & L*/Feb. & F*/Mar. & M/Mar. & L/Mar. & F/Apr. & M/Apr. & L/Apr. & F/May \\
\hline days after turn-green & 0 & 8 & 18 & 28 & 39 & 49 & 59 & 69 & 79 \\
the average RLAI & 0.180 & 0.210 & 0.345 & 0.480 & 0.620 & 0.880 & 1.000 & 0.980 & 0.795 \\
\hline
\end{tabular}

\footnotetext{
${ }^{*}$ M means Middle 10 days; L means Last 10 days; F means First 10 days. The below is same meaning.
} 
The leaf area index of the winter wheat is a continuous process changes according to the period of duration, but with distinct phases and turning points. In its early stage of growth (emergence-overwintering), the leave area index increases slowly, basically showing a linear growth; during the overwintering, the winter wheat almost stops growing. During this period, some green leaves withered, the field measurement became difficult because of the uncertainty of conversion of leaf area. After the winter wheat has turned green and entered the parallel stage of nutrition growth and reproductive growth, the speed of leave area index growth fits the typical Logistic curve until the winter wheat matures. After turning green, the variation of the normalized leaf area index RLAI of the winter wheat can be expressed as:

$$
R L A I=\frac{a}{b+E X P\left(c+d t+e t^{2}\right)}
$$

Where, the RLAI stands for the normalized leaf area index, $\mathrm{t}$ for the days after the stage of turned green, a, b, c, d, e for the undetermined coefficients.

Using the SAS statistical methods to match the data from 20122013, the Logistic formula of days the normalized leaf area index (RLAI) changing after leaves turning green $(t)$ is:

$$
R L A I=\frac{0.1667}{-0.8991+E X P\left(0.6267-0.0182 \times t+0.000146 \times t^{2}\right)}
$$

\subsubsection{Zhu Ma Dian RLAI Calculation and Analysis}

To calculate the average number of the leaf area indexes from the past two years based on the leaf area data collected by Zhu Ma Dian Monitoring Station from 2012-2013, it uses formula (2) to calculating RLAI and analyzing them, the results are as follow:

Table 2 The Relative Leaf Area Index(RLAI) in 2012-2013a

\begin{tabular}{cccccccccc}
\hline Time & M/Feb. & L/Feb. & F/Mar. & M/Mar. & L/Mar. & F/Apr. & M/Apr. & L/Apr. & F/May \\
\hline Days & 10 & 18 & 28 & 38 & 49 & 59 & 69 & 79 & 89 \\
RLAI & 0.225 & 0.357 & 0.421 & 0.712 & 0.717 & 1.000 & 0.942 & 0.433 & 0.404 \\
\hline
\end{tabular}

$$
R L A I=\frac{0.0703}{-0.4384+E X P\left(0.0838-0.0259 \times t+0.000224 \times t^{2}\right)}
$$

As can be seen, the maximum value of RLAI in Xin Xiang, Zhu Ma Dian appeared 55 to 60 days after the winter wheat turned green (normally, the winter wheat in Xin Xiang turns green around 20th February and 10th, February in Zhu Ma Dian), which is the vigorous growth period when the winter wheat jointing and booting, completely reflects the growing period features of winter wheat in north and south. Therefore, it is feasible to using the days after the winter wheat has turned green as a parameter to conduct RLAI retrieval.

\subsubsection{RLAI Distribution and Calculation of the Major} Wheat-Producing Areas in Henan Province

By studying the RLAI of Xin Xiang (north of Henan province) and Zhu Ma Dian (south of Henan province) monitoring stations, it can be concluded that the maximum value of LAI in Xin Xiang appeared around 15th, April and 5th, April in Zhu Ma Dian. The date of maximum value of south and north has 10 days gap. Therefore, the regional distribution map of the number of days after leaves turning green where the maximum value of LAI of the major winter wheat producing area in Henan Province can be calculated by the interpolation method.

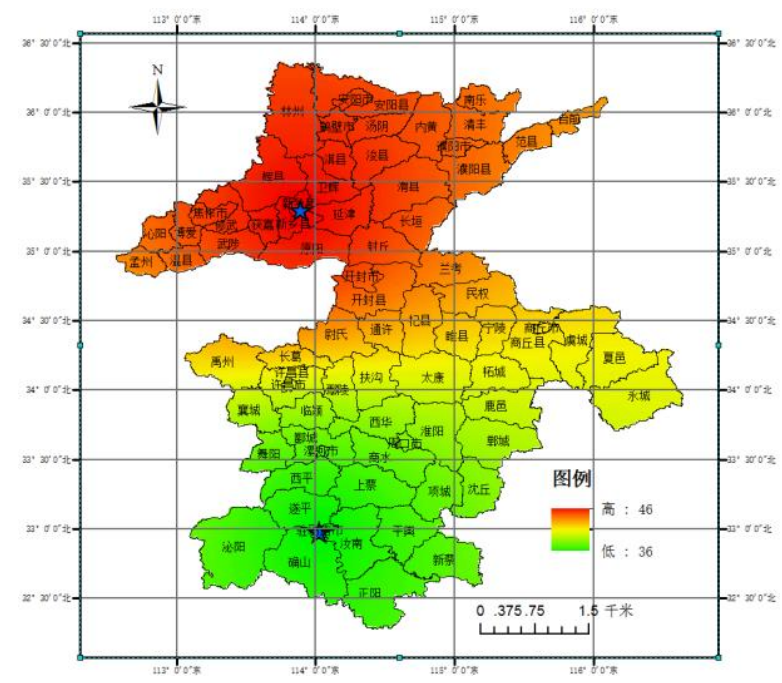

Figure 2 The distribution map of the number of days of leaves turning green where the maximum leaf area index appeared

From the distribution map, it can be observed that there is a difference between the south and the north in terms of the number of days of leaves turning green where the maximum value of winter wheat LAI appeared. For the sake of calculation, $34^{\circ} 30^{\prime}$ northern latitude is taken as the borderline, the southern Henan Province uses the RLAI of Zhu Ma Dian to conduct 
MNDWI calculation and northern Henan uses the RLAI of Xin Xiang to conduct MNDWI calculation. Meanwhile, its correlation with the soil moisture content is also studied.

\section{VERIFICATION OF THE EFFECT}

Selecting three days with no clouds \& frog infecting in the time of winter wheat growing from 2012-2013a, namely, March 11, 2012, May 16, 2013 and May 20, 2013 where wheat was in its vigorous growing period, using the MODIS 1-7 channel spectroscopic data acquired by ENVI 5.0 from 3 times and combining the average soil moisture monitoring data collected from the automatic soil moisture station $10-30 \mathrm{~cm}$, the relevant analysis is as follows (see table 3 ).

The analysis shows that, the effect of the modified normalized difference water index (MNDWI) which has been corrected by the Leaf Area Index was enhanced under different vegetation coverage. This is more obviously seen in May when the vegetation coverage is high.

Table 3 The Comparison Between the Regression Results of NDWI \& MNDWI

\begin{tabular}{|c|c|c|c|c|c|c|}
\hline Date & Index & The regression equation & $\mathrm{R}^{2}$ & F value & Prob> F & $\begin{array}{l}\text { No. of } \\
\text { samples }\end{array}$ \\
\hline \multirow{2}{*}{ 2012/03/11 } & NDWI & $y=10.59 x+14.588$ & 0.5168 & 38.5 & 0.05 & 50 \\
\hline & MNDWI & $y=24.268 x+14.771$ & 0.5343 & 41.3 & 0.05 & 50 \\
\hline \multirow{2}{*}{$2013 / 05 / 16$} & NDWI & $y=6.6087 x+10.372$ & 0.0766 & 4.3 & 0.05 & 50 \\
\hline & MNDWI & $y=27.734 x+9.1114$ & 0.5213 & 56.6 & 0.05 & 50 \\
\hline \multirow{2}{*}{$2013 / 05 / 20$} & NDWI & $y=9.236 x+9.7839$ & 0.3312 & 22.3 & 0.05 & 50 \\
\hline & MNDWI & $y=22.542 x+10.222$ & 0.5201 & 48.8 & 0.05 & 50 \\
\hline
\end{tabular}

Using ArcGIS10 to make the soil moisture observation in situ,

follow:

MNDWI and NDWI into a distribution map, the results are as
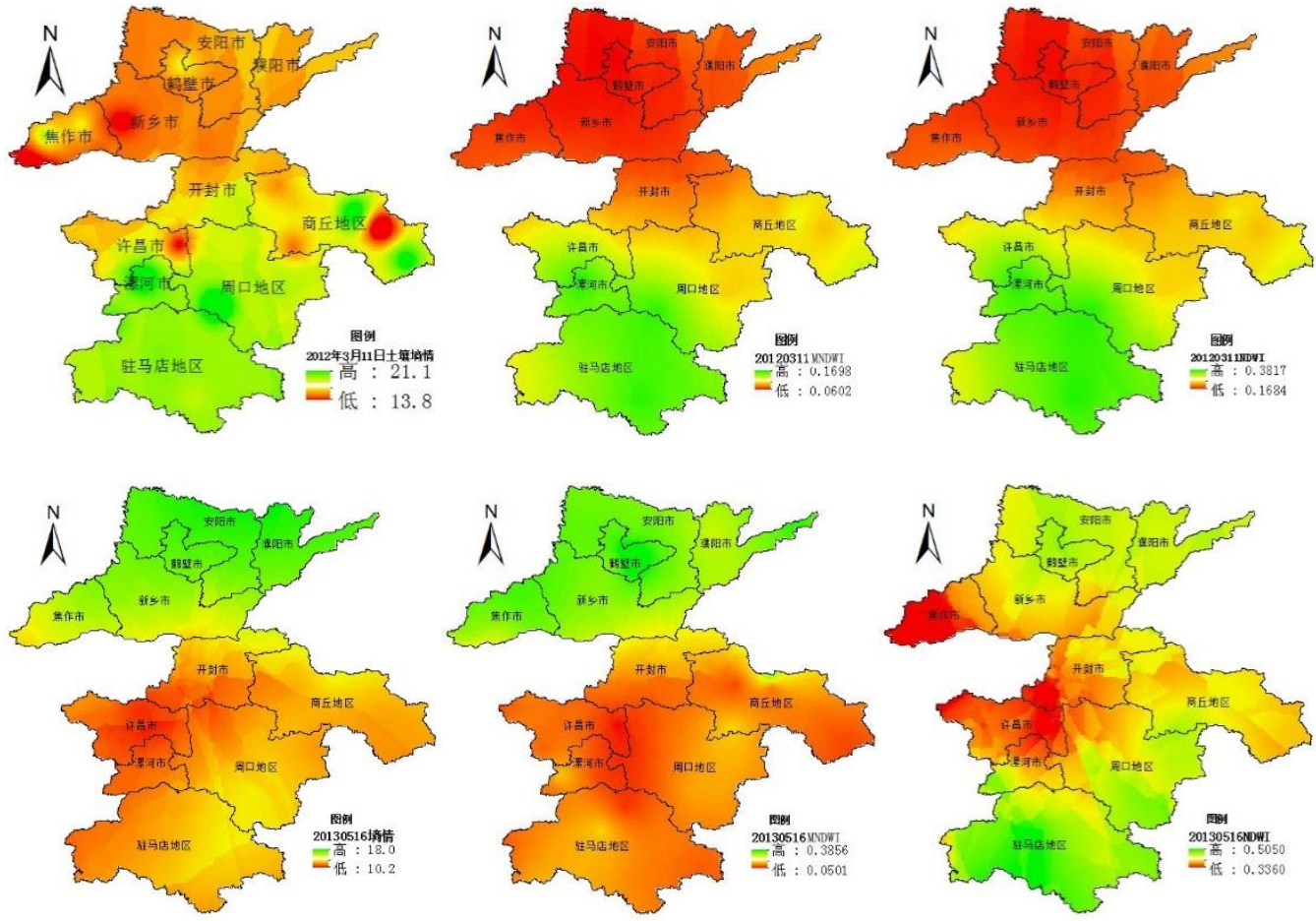

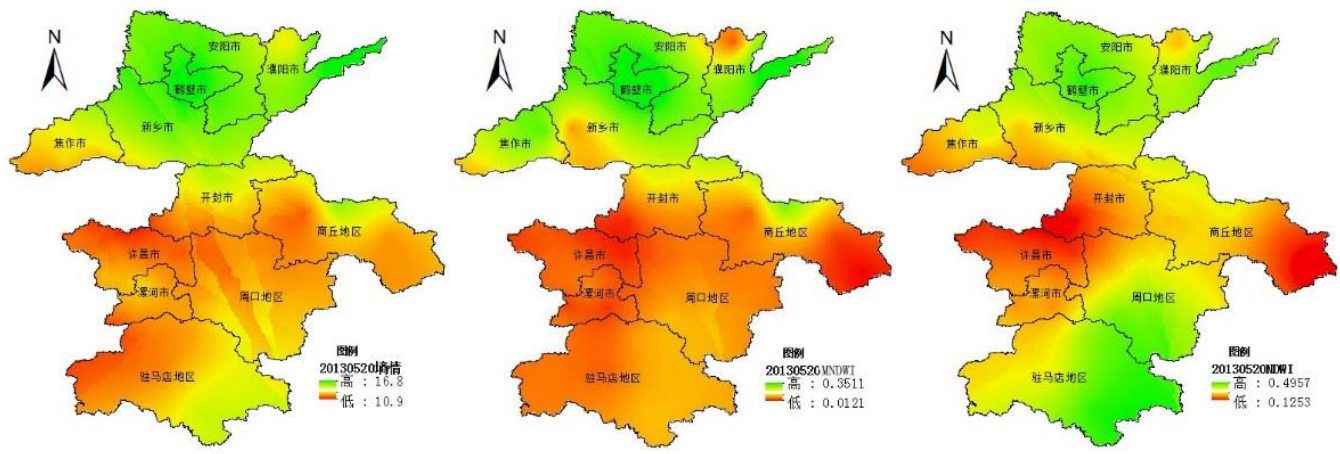

Figure 3 The distribution map of soil moisture, MNDWI, NDWI on March 11, 2012, May 16, 2013 and May 20, 2013

The distribution maps shows that, in March 2012, there is less soil moisture content in northern Henan province, the distribution of NDWI and MNDWI is consistent with the soil moisture content, but MNDWI has better effect; in May 2013, there is less soil moisture content in southern of Henan, the distribution effect of MNDWI is clearly better than that of NDWI.

\section{CONCLUSIONS AND DISCUSSION}

The results show that, NDWI and MNDWI can better reflect the distribution of soil moisture conditions. But the MNDWI with correction can effectively reduce the delay of response with the increase of vegetation coverage, because it has taken the impact of vegetation coverage on spectrum variation. It can also reduce the impact of plant saturation on soil moisture retrieval accuracy. This index can be used for real-time retrieval of soil moisture, which is important to the monitoring, warning of drought.

However, because the paper only takes two sites of RLAI in north and south of Henan province to calculate, the representativeness is not typical enough. This problem can be solved by increasing the number of monitoring stations on Leaf Area Index and establishing different regional models to further improve the retrieval accuracy of the soil moisture of MNDWI. The accumulated temperature from different sites can also be used to establish statistical model with Leaf Area Index (LAI) to acquire the Relative Leaf Area Index (RLAI) from different regions. In this way, the retrieval accuracy of the regional soil moisture under different coverage can be effectively improved.

\section{ACKNOWLEDGEMENTS}

It is jointly funded by the Twelfth-Five science and technology support project of the Ministry of Science and Technology "Study on Key Technologies of Important Agro-meteorological
Disaster Prediction" (2011BAD32B02) and major science and technology projects of Henan province (121100110900).

\section{REFERENCES}

Bo-CaiGao 。NDWI-A Normalized Difference Water Index for Remote Sensing of Vegetation Liquid Water From Space[ J ]. Remote Sensing of Environment, 1996, 58:257-266.

Ceccato P , Flasse S , Gregoire J M. Designing a Spectral Index to Estimate Vegetation Water Content from Remote Sensing Data : Part 2. Validation and applications [ J ] . Remote Sensing of Environment , 2002 ， 82 (2/3) :198-207

Ceccato P , Gobron N , Flasse S , et al. Designing a spectral Index to Estimate Vegetation Water Content from Remote Sensing Data: Part 1, Theoretical approach [ J ] . Remote Sensing of Environment , 2002, 82 (2/ 3):1882197

Cheng Yu, Chen Fu, Liu Qin Huo. The feasibility study of soil moisture monitoring based on MODIS data under different vegetation coverage [j]. Journal of Remote Sensing, 2006, 10 (5): 783-788.

Di, L., Rundquist, D.C., Han, L., 1994.Modeling relationships between NDVI and precipitation during growth cycle. International Journal of Remote Sensing 15 (10):21212136.

Du Xiao , Zhou Yi , Wang Shi-xin, et al. Monitoring and Spatio-Temporal Evolution Researching on Vegetation Leaf Water in China [ C] . International Geoscience and Remote Sensing Symposium (IGARSS) , Anchorage , Alaska , USA , 2004 
Kogan, F.N., 1990. Remote sensing of weather impacts on vegetation in non-homogeneous areas. International Journal of Remote Sensing 11 (8):1405-1419.

Liu Wei, Shi Jian Cheng, Wang Jian Ming. The application of polarimetric decomposition technology in the estimation of soil moisture variation in the vegetated terrain [j]. Application of Theories, 2005, (4): 3-6.

Liu, W., Ferreira, A., 1991. Monitoring crop production regions in the Sao Paulo State of Brazil using normalized difference vegetation index. Proc. 24th. International Symposium on Remote Sensing of Environment,

Rio de Janeiro, Brazil, vol. 2, pp. 447-455. 27-31 May.

Nemani, R., Price, L., Running, S., Goward, S., 1993. Developing satellite derived estimates of surface moisture status. Journal of Applied Meteorology 32 (3):548-557.

Peters, A.J., Walter-Shea, E.A., Lei, J., Vina, A., Hayes, M., Svoboda, M.R., 2002. Drought monitoring with NDVI-based standardized vegetation index.
Photogrammetric Engineering and Remote Sensing 65 (1):7175.

Unganai, L.S., Kogan, F.N., 1998. Drought monitoring and corn yield estimation in Southern Africa from AVHRR data. Remote Sensing of Environment 63 (3):219-232.

Wang Lei, Li Zhen, and Chen Quan. The application of MPDI of soil moisture retrieval in the microwave radiometer vegetation coverage area [j]. Journal of Remote Sensing, 2006, 10 (1): 3438.

Yang, L., Wylie, B.K., Tieszen, L.L., Reed, B.C., 1998. An analysis of relationships among climate forcing and time-integrated NDVI of grasslands over the U.S. northern and central Great Plains. Remote Sensing of Environment 65 (1): 25 37.

ZHOU Peng, DING Jianli, WANG Fei et al. Retrieval methods of soil water content in vegetation covering areas based on multisource remote sensing data [J], Journal of Remote Sensing, 2010, 14(5):961-965. 